\title{
ENVIRONMENT FOR DESIGN AND ANALYSIS OF SYSTEM INTEGRATION
}

\author{
Marcius F. Carvalho \\ Technological Center for Informatics Foundation - CTI \\ Visiting Professor of Mechanical Engineering Faculty-UNICAMP-email:marcius@ia.cti.br \\ Carlos Machado \\ Mechanical Engineering Faculty-UNICAMP-email:cmachado@fem.unicamp.br \\ BRAZIL
}

\begin{abstract}
This paper presents a prototype of an environment to support design and analysis of systems integration. It combines descriptive and analytical methods for the modeling and engineering of system integration. The environment comprises a specialized modeling language for representing a certain class of information, and a modeling methodology for representing, maintaining, and using the information so represented. The system analysis is performed in different levels to consider the static and dynamic aspects. An example of application is presented.
\end{abstract}

Keywords: Information system, Enterprise Modeling, Supply Chain, Planning

\section{INTRODUCTION}

A major motivation for companies to vertically integrate was the desire to control critical activities in the chain of supply (Kogut, 1985 Kumpe and Bolwign, 1988). But it is recognized that vertical integration is declining compelled by globalization and need of rapidly technological changes (Thackray, 1986). The enterprises are looking for competitive advantage by promoting the vertical disintegration, outsourcing non-core activities through world-wide subsidiaries or partnerships, working with their suppliers and customers and engaging themselves in their own core business. In this way, the production environment requires the formation of strategic alliances between companies including dynamic co-operative agreements focused on intersections of market interest.

With the emergency of this new manufacturing philosophy grows the Supply Chain concept. A supply chain can be defined as a network of autonomous or semiautonomous business entities collectively responsible for the procurement, manufacturing and distribution activities associated with one or more families of related products (Reid, 1999). Then a supply chain means inter-company processes and relationships. 
One important aspect, to get success with this production configuration, is to define the integration of the systems participating of the chain, model the interrelation among partners, and manage it. The dynamic characteristics of this production system are requiring continuous improvement in the process of providing services and products requested by the customer. The question that can be raised is how pairs or even larger groups of companies can co-ordinate their individual activities to make things better for everybody?

This paper describes a prototype of an environment to support design and analysis systems, compliant with CIMOSA and PERA system life cycle. It combines descriptive and analytical methods for modeling and engineering of system integration.

\section{SUPPLY CHAIN STRUCTURE}

As manufactured products become more complex, it demands more and more resources being increasingly shared between the suppliers. Figure 1 illustrates a set of enterprises, representing a supply chain, that have to co-operate among themselves looking for achieving more efficiency than as a single isolated enterprise. Supply Chain (SC) means inter-company business processes and relationships and is concerned with co-ordination of the synergy among companies, establishing individual activities to make things better for everybody.

The members of a chain can change dynamically with time due to new market requirements or economic decisions. An enterprise can be momentarily out of the group or can co-operate with more than one supply chain. Also, co-operation can involve regional or global groups of enterprises (Figure 1).

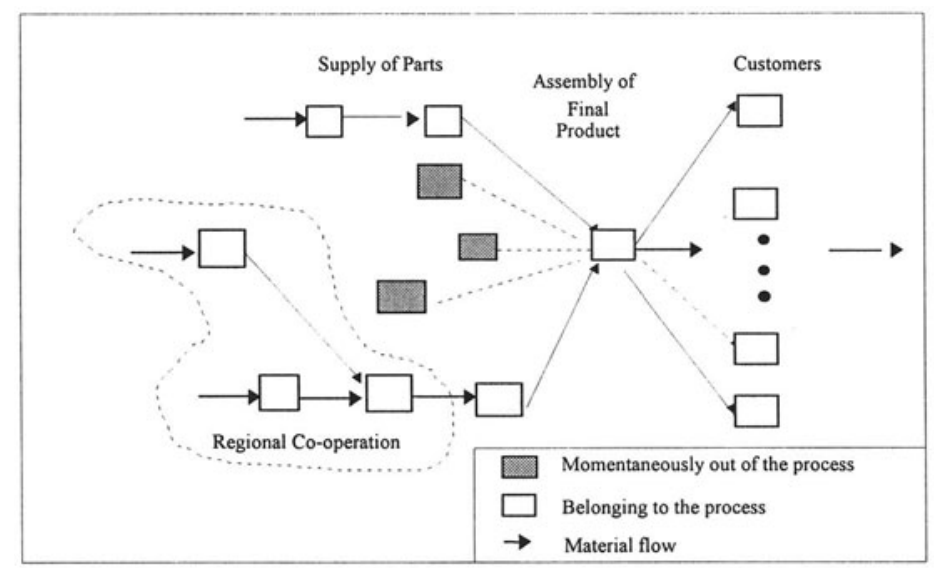

Figure 1 - Supply Chain Structure

Forrester (1961) examined a production-distribution system whose component echelons were a factory, a warehouse, a distributor, and retailers. Forrester used flow simulation of goods, information, and delays in the system and concluded that if demand of products are transmitted along a series of inventories using stock control ordering, the demand variation will increase with each transfer (Figure 2). This 
demand behavior is termed "the Forrester effect" and describes how real demand information can be distorted as it is interpreted, processed, and passed up the chain.

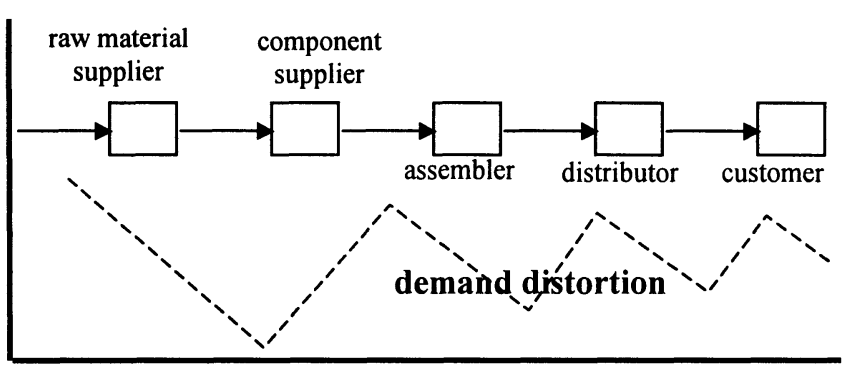

Figure 2 - Forrester Effect

Evans et. al.(1993) suggested that backward integration could result in a greater advantage to those suppliers at the end of the chain and consequently to the whole chain. Although this integration improves the behavioral of a chain it does not guarantee the same level of information to all SC components and the Forrest effect still exist.

For a consortium of enterprises to become efficient, integrative, communicative and organizational interaction among the members of a chain must be implemented as suggested below.

\section{THE PROPOSAL FOR AN ORGANIZATIONAL STRUCTURE}

In the SC strategic configuration the competition is been typified less by firm versus firm and more by supply chain versus supply chain. Then in this organizational structure, a singular enterprise gives place to a more complex organizational arrangement, with amplification of the enterprise concept to a network of enterprises.

The internal enterprise integration evolves to internal supply chain integration. Each agent of a supply chain, to perform his part of the job, has to modify his plans to meet commitments in light of random problems such as: machine failures, scrap, power outages, emergency jobs or even external change or failures in the Supply Chain. Stabilizing the demand and inventory across the SC can reduce substantially the manufacturing production cost.

This paper, taking advantage of the availability of web-enabled technology, suggests a two level hierarchical decision environment for the planning (Figure 3). The first level, named co-operative supply chain level (Carvalho and Campos, 1997), considers the co-operative decisions and actions taking into account the constraints and goals of each individual enterprise of the chain.

At the second action level, enterprise level, each enterprise manages its own actions taking into account the target established by the co-operative level. With this management structure the performance and the competitiveness of the agents 
belonging to a supply chain can be improved and the Forrester effect can diminish since each member of the supply chain has the same level of information.

\section{Co-operative Supply Chain Structure (CSC)}

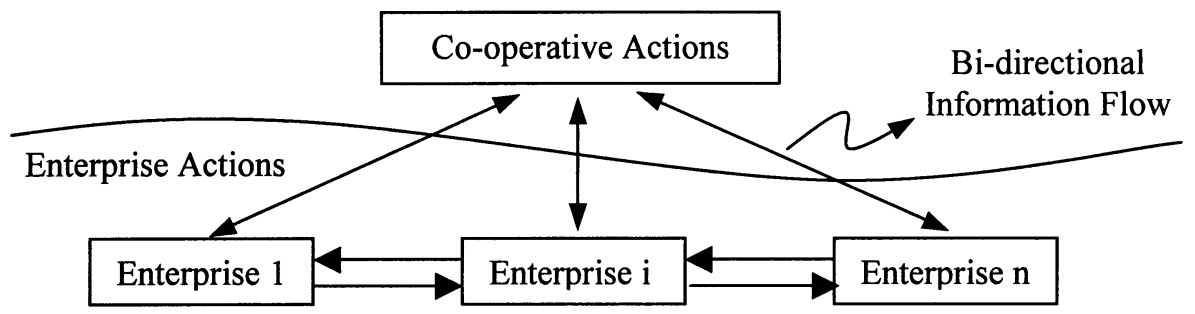

Figure 3 - Structure for a Co-operative Supply Chain

This new managerial support configuration for a multi-enterprise, multi-stage and multi-product system has to reflect the dynamics behavior and improve the agility and flexibility of the decision process.

\subsection{Co-operative Supply Chain (CSC)}

Using the above model to represent the structure of the co-operative group, each partner should have access to the future co-operative actions to be implemented for its enterprise. When a participant of the co-operative group request for an action (it can be communication of failure, new orders, etc.), it goes to the co-operative level. The co-operative level receives the co-operative actions and determines new planning to the enterprises that had their previous actions modified. So, enterprises that are not influenced by this request are not disturbed. But, at the same time the cooperative level must guarantee information to those enterprises, near and far of the requested enterprise, that have their previous actions modified.

Enterprises belonging to the supply chain cannot refuse to participate of defined co-operative action. This means that the negotiation of price and capacity occurs before the formation of the CSC. But an enterprise interested in leaving CSC can discontinue its participation (not sharing information and production capacity) has to finish the previously established actions. With the request for quitting an enterprise can disconnect the CSC. The implementation of this request can result in two disconnected sub-CSC breaking the exchange of information and material flow between them. The chain has to be re-organized and the responsibility for reorganizing the new system to a coherent state is at the CSC level.

With this management structure, some desirable actions can be reached as (Inger, 1995): shorten planning cycle; reduce lead times; increase replenishment frequency; reduce batch size; split stocks to fit several markets. The first step for integration is to understand each component of the chain, its similarities and diversities. Then there is a growing need, in this heterogeneous system, to have a common representation in such a way everybody of the group can understand all the others. The modeling process will represent or model the physical system and is presented in the next section. 


\subsection{The modeling process}

The modeling process comprises a sequence of activities to build models based on specialized modeling languages and methodology supported by a computerized tool. The modeling language is a set of computer-based structures that represent a certain class of information. It has both a syntax and semantics: a set of rule that determines the legitimate syntactic constructs of the language. And a set of rules that determines the syntax and semantics meaning of those constructs and define which language is more adequate and competent for the purposes and goals of the modeling task. The methodology provides a set of structured engineering activities to build, maintain, use and reuse the models, helping the designers on the modeling process. The computational tool facilitates the design, analysis, construction, and management of the models. There are three important aspects to be considered on these computerized tools: the resources to support design, to support analysis and to manage the models (Mylopoulos, 1998).

The model is built during the design process. One or more languages can represent the model. Moreover, the design process has its own rules to guarantee a well-structured model building. So, the design tool must consider aspects related to the languages used to represent the enterprise model and the modeling methodologies that guide the design process.

The purpose of an analysis tool is to verify the model consistency and validity, before a model is used. The consistency of the model can be verified through checking. The checking comprises a set of activities that verify if the symbolic structures in the model satisfy syntactic and semantic rules. Models based on dynamic ontologies have additional consistency analysis that considers dynamic properties like termination, liveness, reachability. The model validity considers the consistency of the model with respect to its application.

A management tool should support the designers on model building and maintenance. Moreover, the tool should manage the project complexities like project teams with interdisciplinary expertise sharing the design and analysis process; model reuse, model implementation and releasing.

The concepts described above, the modeling languages, the methodologies and the computational tools with the purpose to model enterprises form an architecture of Enterprise Modeling. Some consolidated architectures are ARIS (Scheer, 1992), CIMOSA (AMICE, 1993) and PERA (Williams, 1994).

\section{THE ENVIRONMENT}

A prototype of an environment was developed to design and analyzes system integration and is based on CIMOSA Architectural Framework. It covers two stages of CIMOSA life cycle (requirement definition and design specification modeling levels), and four views: function, information, resource and organization view.

The diagram editor and template editor support the activities of model definition. A checking tool, that verifies the correctness of the model, supports the analysis. It verifies the consistency and dynamics of the enterprise's function. The consistency is related to the correctness of the constructs and their relationships. The dynamic is 
related to the temporal behavior of material and information flow in the functional view.

The environment offers facilities to integrate the flow of material and the flow of information on the functional view to represent the actual dynamic of the model to be analyzed through a simulation tool. The integration should avoid redundancy, be consistent, and accommodate a variety of user needs and modeling goals.

Considering the management aspects, the environment handles partial models, and other tested components from old projects. This ability can speed up the enterprise design and reengineering process. It avoids the project team to analyze a set of factors that have already been analyzed either by a previous team or by a software vendor.

\section{CSC MODEL}

This section presents a functional model of a CSC developed on the environment described above. This model focuses on the information flow of coordination between the co-operative enterprises. The flow of material is only indicated in Figure 4, but not considered any further.

The domain (Figure 4) represents the CSC with two organizational levels. The Domain Process 'Co-operative Management' considers the set of co-operative actions and coordinates the activities of the chain. For simplicity, only three companies and one customer are considered in the model. The customer order triggers the co-operative actions, that based on information provided by the cooperating companies, takes decisions to satisfy the customer requirements. These decisions are communicated as targets to those companies that had their previous plans modified.

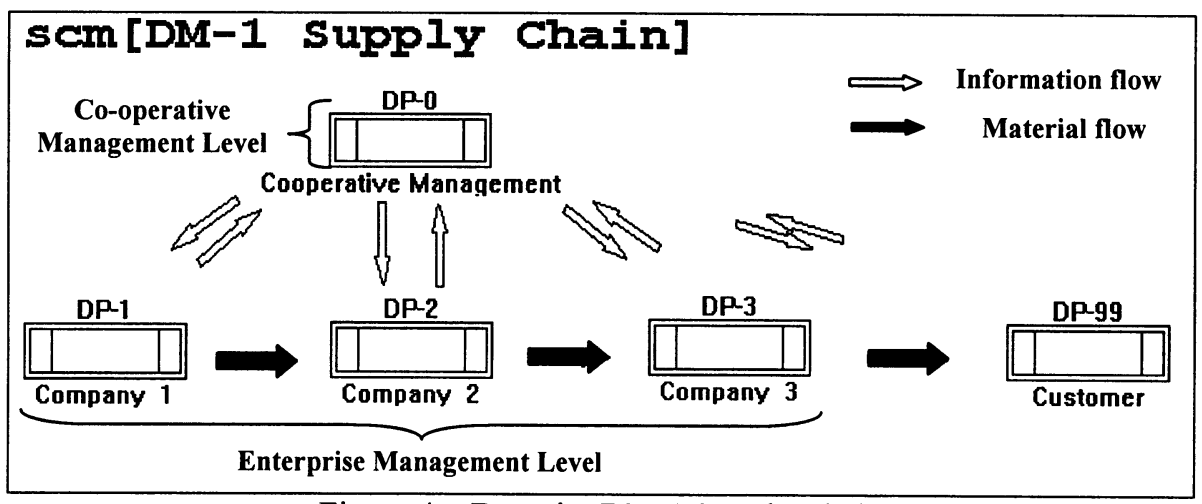

Figure 4 - Domain: DM-1 Supply Chain

The Figure 5 represents the functional decomposition of the Domain Process DP0 . In this diagram, the customer orders trigger the optimization planning process (Carvalho, M.F. et. al. 1999) where, the capacities of the enterprises are considered. The co-operative management level communicates the plan to the companies involved. If the local constraints make the plan infeasible, it calls for negotiation with the customer, looks for other partners that could add value to the SC and 
informs the co-operative level the unfeasibility to meet the targets. The co-operative management level receives status information from the companies periodically. Machine failures, scraps, power outages, emergency jobs, capacity changes are critical events and have direct impact on customer dissatisfaction. Therefore, the plan must be redefined to consider the new production scenario.

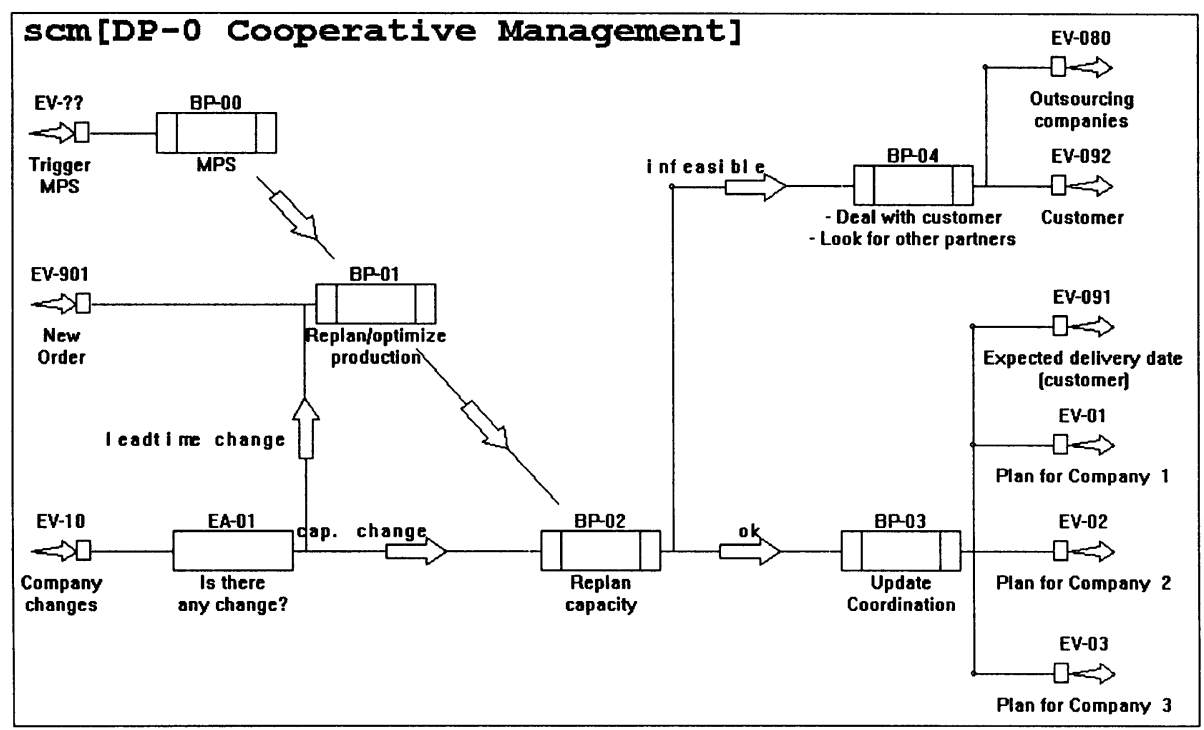

Figure 5 - Diagram representing the Co-operative Management Processes

Each company (Figure 6) receives, from the co-operative management level, targets that must be pursued by its internal planning activities. After the planning, the company schedules and releases its operation. A critical event that potentially violates the feasibility of the present plan must be communicated to the co-operative management level.

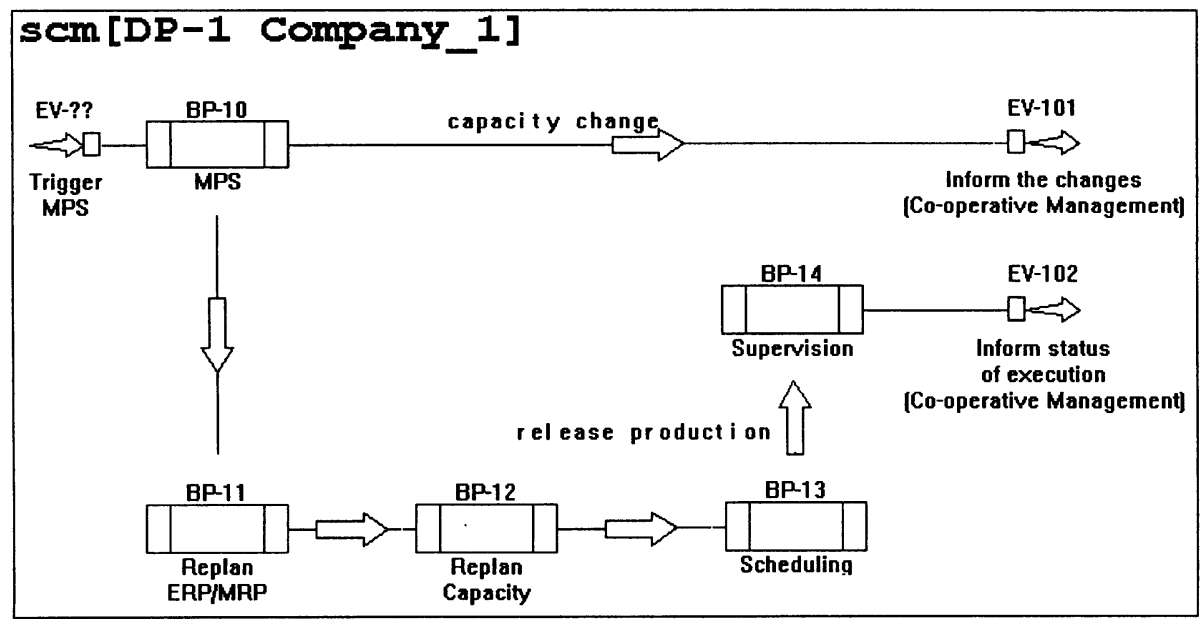

Figure 6 - The diagram represents the process carried out by the Company 1 
Local problems can be solved through negotiation with neighborhood enterprises. In this way, the co-operative companies have more time to re-plan and reschedule their operations to better adjust to the new scenario. In a more complex scenario, where a product life cycle plays an important role, the enterprises need to know how to allocate the resources on design, process planning, manufacturing, and shipment of their product mix.

\section{CONCLUSION}

This paper suggested a two level hierarchical decision structure named the Cooperative Supply Chain (CSC) environment. The first level, co-operative supply chain level considers the co-operative decisions and actions taking into account the constraints and goals of each individual enterprise of the chain. At the second action level, enterprise level, each enterprise manages its own actions taking into account the target established by the co-operative level.

The first step to implement the suggested structure is to understand each component of the chain, its similarities and diversities through an enterprise modeling process that combines, modeling languages, methodologies and computational tools. This paper presented a prototype of an environment to support the design and analysis of the supply chain system integration. A model for production planning activities of CSC based on CIMOSA was also presented.

\section{REFERENCES}

1. AMICE. CIMOSA: Open System Architecture for CIM, 2nd revised and extend version. SpringerVerlag, Berlin., 1993

2. Carvalho,M.F., Fernandes,C.A.O., Ferreira, P.A.V. Multiproduct multistage production scheduling (MMPS) for manufacturing systems. Production Planning \& Control 1999; 10(7): 671-681.

3. Carvalho,M.F., Campos,R. A Hierarchy for Cooperative Management and Control of Production and Logistics, $M C P L$, August, 1997; 420-425

4. Evans, G.N., Naim, M.M., Towill, D.R. Assessing the impact of information systems on dynamic supply chain performance. Logistics Information Management 1993; 6: 15-25

5. Forrester, J.W. Industrial Dynamics, MIT Press, Boston, MA, 1961

6. Harland, C. The dynamics of customer dissatisfaction in supply chains. Production Planning \& Control 1995; 6(3): 209-217

7. Inger, R. et. al. Creating a manufacturing environment that is in harmony with the market - the 'how' of supply chain management. Production Planning \& Control 1995; 6(3): 246-257

8. Kogut, B. Designing global strategies: comparative and competitive value added chains. Sloan Manufacturing Review 1985, Summer: 15-28

9. Kumpe, E., Bolwijn, P.T. Manufacturing: the new case for vertical integration. Harvard Business Review 1988, March/April: 75-81

10. Mylopoulos, J. Characterizing Information Modeling Techniques, p. 17-57. In: Handbook on Architecture of Information Systems (eds. Bernus, P., Mertins, K. Schmidt, G.), Springer-Verlag, Berlin, 1998

11. Reid, R.L. Engineering the Virtual Enterprise. URL: http://arrirs04.uta.edu:80/eif/ve_ie.pdf, 1999

12. Scheer, A-W. Architecture for Integrated Information Systems. Springer-Verlag, Berlin, 1992

13. Thackray, J. America's vertical cutback. Management Today. Proceedings of the Institutional of Mechanical Engineers 1985; June(206): 233-245

14. William,T.J. The Purdue Enterprise Reference Architecture. Computers in Industry 1994; 24(2-3): p.141-58 